\title{
VEINTICINCO AÑOS DE DERECHO DE PARTIDOS
}

\author{
ENRIQUE ÁLVAREZ CONDE
}

Catedrático de Derecho Constitucional

Universidad Rey Juan Carlos 


\section{SUMARIO}

I. El Derecho de Partidos. II. Los principios del Derecho de Partidos. 1) El principio de libertad. 2) El principio del pluralismo político. 3) El principio de constitucionalidad. 4) El principio de proporcionalidad. 5) El principio de intervención mínima. III. EL CONTENIDO DEL DERECHO DE PARTIDOS. 1) Los partidos políticos y los principios y valores constitucionales. 2) Los partidos políticos y los derechos fundamentales. 3) El régimen jurídico de los partidos políticos. 4) Los partidos políticos y el Derecho Electoral. 5) Los partidos políticos y el Derecho Parlamentario. 6) La financiación de los partidos políticos. 


\title{
VEINTICINCO AÑOS DE DERECHO DE PARTIDOS
}

\author{
POR \\ ENRIQUE ÁLVAREZ CONDE \\ Catedrático de Derecho Constitucional \\ Universidad Rey Juan Carlos
}

\section{EL DERECHO DE PARTIDOS}

Hoy resulta comúnmente admitido que cualquier disciplina científica que pretende adquirir la condición de tal debe reunir una serie de requisitos. Así, en primer lugar habria que hablar de la existencia de unas fuentes de conocimiento propias. En segundo lugar, una serie de principios característicos de la misma, que tengan un carácter informador y desde los cuales se proceda a la interpretación de su contenido. En tercer lugar, la presencia de un contenido propio y delimitado. Y, finalmente, la consagración de las correspondientes instancias jurisdiccionales que sirvan de garantía del mismo. Con ello se puede hablar de la existencia de un régimen normativo propio, expresamente reconocido por la Sentencia del Tribunal Constitucional 48/2003, de 12 de marzo, pues de otra forma estariamos privando al art. 6 CE de su condición de norma jurídica, calificándola de una simple proposición normativa. Y ello porque dicho precepto permite tanto un tratamiento común de los partidos dentro del régimen jurídico asociativo como un tratamiento especifico y diferenciado, debido a la relevancia constitucional de los mismos. Ello es consecuencia directa del llamado "privilegio de partidos», característico de otros ordenamientos jurídicos, como el alemán, y que entre nosotros tiene un significado muy diferente, pues las manifestaciones concretas de aquel no se producen con la misma intensidad y significado en nuestro sistema jurídico. 
La constitucionalizacion de los partidos se produce por vez primera en nuestra historia constitucional (pues durante la Constitución de 1931 únicamente se hablaba de "facciones políticas») en el art. 6 CE cuando dispone: "Los partidos políticos expresan el pluralismo politico, concurren a la formación y manifestación de la voluntad popular y son instrumento fundamental para la participación política. Su creación y el ejercicio de su actividad son libres dentro del respeto a la Constitución y a la ley. Su estructura interna y funcionamiento deberán ser democráticos». Junto a este precepto habria que mencionar también el art. 22 donde se constitucionaliza el derecho de asociación política y, en menor medida, el art. 99, donde se habla de grupos políticos.

El primer "desarrollo legislativo" del precepto constitucional fue debido a la ley formalmente preconstitucional 54/1978, de 4 de diciembre, de Partidos Políticos, cuyos orígenes hay que situar en los Pactos de la Moncloa, que establecía un régimen de mínimos, fuertemente criticada por la nuestra doctrina científica, que tanto nuestra jurisprudencia constitucional como ordinaria se encargaron de ampliar considerablemente.

Esta normativa preconstitucional ha sido derogada por la Ley Orgánica 6/2002, de 27 de junio, de Partidos Políticos (en adelante LOPP), que fue recurrida por el Gobierno vasco ante el Tribunal Constitucional y declarada plenamente conforme con la Constitución por la Sentencia 48/2003, de 12 de marzo. Se trata, además, de una ley que ya ha sido objeto de una aplicación práctica con motivo del proceso de ilegalizacion de Batasuna y de las pasadas elecciones del 25 de mayo del 2003, dando lugar a una importante, y no siempre exenta de contradicciones, jurisprudencia constitucional y ordinaria, y al planteamiento de nuevos problemas institucionales, cuya solución aun no parece vislumbrarse. Pero también hay que decir que su aplicación no ha producido los efectos catastrofistas que algunos anunciaban, pues la ilegalización de Batasuna, acordada por la Sentencia del Tribunal Supremo de 27 de marzo del 2003, actualmente recurrida en amparo ante el Tribunal Constitucional, no ha tenido ese carácter traumático que algunos pretendian y el desarrollo de los procesos electorales del 25 de mayo han registrado el mismo grado de normalidad política que los anteriores. Se trata, pues, de una ley, condicionada por dicho proceso de ilegalización, claramente política, pero también de desarrollo del art. $6 \mathrm{CE}$, que jurídicamente no puede ser calificada como una ley "ad casum" o singular, que va un poco mas allá que la normativa preconstitucional, pero que tampoco puede ser calificada como una norma codificadora del Derecho de Partidos, pese a lo que diga su Expo- 
sición de Motivos. Todo ello sin olvidar que una ley de Partidos Políticos no es una ley cualquiera, pues tiene un marcado carácter político que afecta a la esencia misma del sistema democrático.

Asimismo, habría que mencionar la nueva regulación ofrecida por la Ley Orgánica 1/2002, de 22 de marzo, reguladora del Derecho de asociación (en adelante LODE), actualmente recurrida por el Gobierno catalán, que suponía el desarrollo del art. 22 de nuestra Norma Fundamental. Junto a ella, la regulación propia del Derecho de Partidos se encuentra contenido en una normativa dispersa, como es la legislación sobre financiación de partidos políticos, la normativa electoral, los Reglamentos de las Cámaras parlamentarias, etc. La existencia de toda esta normativa ha puesto de relieve la falta de voluntad codificadora de nuestros legisladores, que han actuado, generalmente, movidos por decisiones políticas y coyunturales.

Después de 25 años de vigencia de un determinado Derecho de Partidos, parece ser que se ha producido un cambio radical en las posturas de nuestras fuerzas políticas mayoritarias. Frente a la tesis inicial de tratar de integrar dentro de la legalidad vigente a todas las fuerzas políticas antisistema e, incluso, defensoras de la violencia y del terrorismo, se ha pasado a un planteamiento de lucha activa contra dicho fenómeno, utilizando todos los resortes que ofrecía el Estado de Derecho, entendiendo que la presencia dentro de la legalidad de las mencionadas fuerzas políticas, en lugar de producir su integrảión dentro del sistema democrático conducía al debilitamiento del mismo, pues únicamente se servían de él para minarlo y debilitarlo. Ahora bien, esta postura política, en sí misma defendible, debe plasmarse jurídicamente con arreglo a los postulados y principios inherentes al propio sistema democrático, no siendo aceptables aquellos planteamientos hechos por otros países que, tras los acontecimientos del 11 de septiembre del 2001, han endurecido, en su respuesta al llamado terrorismo global, radicalmente sus legislaciones sin respetar los postulados de su sistema democrático. Ello no parece haber sucedido en nuestro país, aunque no dejan de plantearse problemas jurídicos importantes. Buena prueba de ello fue el «Acuerdo por las libertades y contra el terrorismo", firmado entre el PP y el PSOE, y al que se adhirieron otras fuerzas políticas, que se convirtió en un instrumento adecuado para la elaboración y el consenso de importantes medidas de naturaleza legislativa y política.

El primero de los problemas jurídicos planteados por nuestro Derecho de Partidos es la falta de voluntad codificadora de nuestros legisladores, pues, como antes apuntábamos, el Derecho de Partidos 
se encuentra disperso a lo largo de una pluralidad y diversidad de normas, sin una clara vocación unitaria, cuya sistematización es necesario realizar, planteando no pocos problemas interpretativos y de integración normativa.

El segundo de ellos, y consecuencia directa del anterior, es la dificil interrelación entre la actual normativa existente, así como su coherencia con el resto del ordenamiento jurídico. A este respecto, merece destacarse lo siguiente:

1) La falta de adecuación entre la LOPP y la LODE, pese a ser dos normas muy próximas en el tiempo, pues ambas mantienen soluciones juridicas diferentes a problemas similares. Pensemos en cuestiones tales como la inscripción y adquisición de personalidad jurídica de partidos políticos y asociaciones, los requisitos para la creación de los mismos (las personas jurídicas pueden crear asociaciones y no partidos políticos, los cuales tampoco puede ser creados por los extranjeros, etc..), la opción por diferentes instancias jurisdiccionales para su control, los problemas derivados de la aplicación supletoria de la LODE, así como las lagunas existentes en la LOPP en temas tales como las obligaciones contables $y$ documentales, las funciones de los liquidadores, el régimen jurídico de los asociados o la modificación de los estatutos. Y es que la existencia autónoma de un Derecho de Partidos no debe desconocer las relaciones entre los arts. 6 y 22 de nuestra Norma Fundamental.

2) La interrelacion existente entre la LOPP y el Código Penal, especialmente cuando este tipifica a las asociaciones ilicitas en los arts. 515 y 520.Y ello no solo porque la LOPP no pueda ser calificada de ley penal, aunque sí de ley sancionadora, pues la disolución de los partidos políticos no es una pena sino una sanción, sino porque quizás. hubiese sido necesario proceder a una modificación de aquel al mismo tiempo que la LOPP, evitando aun mas la posible coincidencia entre los tipos penales y los establecidos en la Ley de Partidos.

3) Las relaciones con las normas procesales, en el sentido de sí la regulación que se efectúa, en el tema de la disolución de los partidos, es un proceso civil o penal. La respuesta que demos afecta a cuestiones tales como la propia competencia de los órganos jurisdiccionales. Lo cierto es que estamos en presencia de un proceso civil con ciertas especialidades, donde no tienen cabida los principios propios del Derecho 
Penal, como pudiera ser la presunción de inocencia de un partido político, no atribuyéndose a la jurisdicción civil, en cambio, la competencia para la disolución de los partidos.

4) La falta de referencia a la financiación de los partidos políticos que, por otra parte, ha sido objeto de reformas parciales, fragmentarias y dispersas, con posterioridad incluso a la aprobación de la actual Ley de Partidos Políticos.

\section{LOS PRINCIPIOS DEL DERECHO DE PARTIDOS}

La existencia de una serie de principios informadores del Derecho de Partidos, concebidos a modo de axiología desde donde debe producirse la interpretación del mismo plantea el problema de su delimitación y significado. Sin perjuicio de la existencia de otros principios, nosotros nos vamos a referir a los siguientes:

\section{El principio de libertad}

Nuestra Constitución estable el principio de libertad de creación de partidos políticos, en su triple vertiente de libertad positiva de creación, libertad positiva de afiliación y libertad negativa de pertenencia o participación, como consecuencia de que los partidos tienen la consideración de asociaciones políticas. Ahora bien, la configuracion del derecho a crear partidos como un derecho de libertad, no implica la ausencia de límites, que ya han sido suficientemente explicitados por la jurisprudencia del Tribunal Europeo de Derechos Humanos (TEDH), tratando de evitar que la defensa del sistema democrático pongan en peligro las bases de ese mismo sistema. Este principio de libertad tiene manifestaciones importantes como es el principio de autonormacion de los partidos políticos a través de sus estatutos, la no injerencia de los poderes públicos en su régimen jurídico y, en general, sirve de principio informador a los demás principios caracterizadores del Derecho de Partidos.

\section{El principio del pluralismo político}

El pluralismo supone el reconocimiento de grupos y formaciones sociales entre el individuo y el Estado, lo cual no debe implicar su 
monopolización por parte de los partidos políticos, aunque sean los protagonistas principales del mismo. Pero lo importante es destacar que el pluralismo no es sólo tolerancia, sino también una defensa explícita de la misma, oponiéndose a quien la niega, pues "tampoco sin pluralismo político concurren dos de los atributos esenciales de la democracia, como son la libertad política o la ley como expresión de la voluntad general" (STEDH de 13 de febrero del 2003). Así se pone de manifiesto en la Sentencia del Tribunal Supremo de 27 de marzo del 2003, señalando que "tiene una dimensión trascendente o informadora del texto constitucional y del ordenamiento jurídico en su conjunto, pero en cierta medida también evoca un rango axiológico superior al que, en principio, pudiera predicarse de los principios constitucionales y de los derechos fundamentales", y que "el pluralismo político no equivale sólo a tolerancia ante la pluralidad o ante la diferencia, sino que el concepto constitucional evoca, mas allá, una actitud comprometida de defensa de la existencia de esa misma pluralidad». El pluralismo político también tiene sus propios límites, como es la utilización de la violencia como método político, tal y como reiteradamente ha establecido la jurisprudencia del TEDH.

\section{El principio de constitucionalidad}

Como es sabido, el art.9.1. CE no sólo supone la superación del principio de vinculación negativa a la ley, sino que establece una vinculación positiva de distinta naturaleza para los poderes públicos y para los ciudadanos. En efecto, mientras los primeros tienen un deber positivo de acatamiento, los segundos solamente tienen un deber negativo. El problema planteado es cuál debe ser la posición de los partidos políticos, dada su condición de asociaciones políticas. La solución no es fácil de precisar, aunque es posible sostener que los partidos políticos se encuentran en una situación intermedia entre los particulares y los poderes públicos, a nuestro criterio más próxima a la de estos últimos, pues el llamado "privilegio de partidos" tiene aquí una manifestación importante. Es decir, dada la posición constitucional de los partidos, les es exigible un plus adicional al de los particulares. El problema consiste en determinar, en nuestro ordenamiento jurídico, en qué consiste ese plus adicional. La cuestión esta directamente relacionada con la teoria de la llamada democracia militante a la que posteriormente nos referiremos. 


\section{El principio de proporcionalidad}

El principio de proporcional no es exclusivo del Derecho de Partidos, sino que afecta a la ponderación de todo el sistema de derechos fundamentales y libertades públicas. Este principio tiene sus manifestaciones más puntuales en cuestiones tales como la diferencia entre la suspensión y disolución de un partido, la tipificacion de sus causas, la adopción de otras posibles medidas cautelares, como la suspensión de la financiación pública cuando un partido no ha sido disuelto o suspendido, etc.

\section{El principio de intervención mínima}

Este principio es consecuencia directa del derecho a la libertad de creación de partidos políticos, que tiene manifestaciones concretas tendentes a evitar una excesiva intervención por parte de los poderes públicos en el régimen jurídico de los partidos políticos. Cuestiones tales como el principio de autoorganización de los partidos y la común tendencia de todos ellos a evitar la intromisión normativa por parte de los poderes públicos se convierten en manifestaciones del mismo.

- La existencia de estos principios, y otros más que pudieran añadirse no debe hacernos olvidar el fenómeno de la constitucionalizacion de los partidos políticos y su significado actual en un mundo globalizado, donde si bien aun continúan siendo los instrumentos principales de participación política, parecen haber perdido en gran medida sus funciones de sociliazacion política y de formadores del pensamiento y de la acción política. Esta situación se contrapone al protagonismo que aun desempeñan los partidos políticos en los respectivos Estados nacionales, configurados como auténticos Estados de partidos, pues como ya dijera el propio KELSEN «la democracia moderna descansa...sobre los partidos politicos, cuya significación crece con el fortalecimiento progresivo del Estado democrático" y que "la democracia necesaria e inevitablemente, requiere un Estado de partidos". Incluso, en ocasiones, los partidos políticos han sido calificados como "soberanos constitucionales", aunque sea difícil hablar jurídicamente de la existencia de un soberano en el Estado constitucional de nuestros días. Pero lo cierto es que su protagonismo en la vida política resulta evidente, pues «debido a su papel, los partidos políticos, únicas formaciones que pueden acceder al poder, tienen además la capacidad de ejercer una influencia sobre el conjunto del régimen de su país. Con sus proyectos de modelo global de sociedad que proponen a los elec- 
tores, y su capacidad de realizar estos proyectos una vez que llegan al poder, los partidos políticos se distinguen de las demás organizaciones que intervienen en la arena política" (STEDH de 13 de febrero del 2003). Es decir, todos parecen ser conscientes de la trascendencia de las funciones que los partidos están llamados a desempeñar en un sistema democrático, lo cual implica también determinadas exigencias y límites que deben englobarse dentro del llamado "privilegio de partidos", y que no deben proyectarse sobre la ideología de los partidos $y$ su compatibilidad con el orden constitucional, sino sobre su funcionamiento y conducta externa en relación con el respeto al orden constitucional y al sistema democrático. Todo ello, sin olvidar que estamos asistiendo a la aparición de un Derecho europeo de partidos políticos, tal y como revelan diversas disposiciones normativas de los Tratados constitutivos de la Unión Europea y la consolidación de una jurisprudencia sobre partidos políticos dimanante del TEDH, quien posiblemente tendrá que pronunciarse, en un futuro inmediato, sobre la Ley de Partidos de nuestro país.

\section{EL CONTENIDO DEL DERECHO DE PARTIDOS}

El contenido del llamado Derecho de Partidos afecta a una pluralidad de cuestiones que rebasan el marco estricto del Derecho Constitucional, adentrándose en disciplinas como la Ciencia Política y la Sociología. Cuestiones tales como el análisis de los sistemas electorales y de los sistemas de partidos son suficientemente explicativas a este respecto. Nosotros únicamente vamos a referirnos a cuestiones puntuales y concretas que consideramos sumamente características del Derecho de Partidos. Entre ellas merecen destacarse las siguientes.

\section{Los partidos políticos y los principios y valores constitucionales}

Anteriormente poníamos de relieve que la aprobación de una Ley de Partidos no es la aprobación de una ley cualquiera, pues la misma afecta a la esencia del sistema democrático. Ello plantea el problema de la relación de los partidos políticos con los principios y valores constitucionales en el sentido que hacíamos referencia al hablar del principio de constitucionalidad. 
Como es sabido, en otros ordenamientos jurídicos, especialmente el alemán, se ha construido la teoría de la llamada "democracia militante" o "die streitbare DemoKratie", que responde a planteamientos históricos concretos y coyunturales, pues el constituyente alemán quiso asegurarse que la mecánica democrática no volvería a ser utilizada para pervertir el orden constitucional establecido. Como consecuencia de ello, en el ordenamiento jurídico alemán, es posible la ilegalización de partidos políticos porque en sus fines y programas pretendan la destrucción del sistema democrático, pues así lo dice expresamente la Ley Fundamental de Bonn en su art. 21.1, cuando proscribe a aquellos partidos que, de acuerdo con sus objetivos o el comportamiento de sus seguidores, pretendan obstaculizar o destruir el libre orden democrático. Ahora bien, esta teoría de la llamada democracia militante o combativa no puede ser extrapolada del contexto histórico en que surgió. Por eso no nos parecen acertadas aquellas posiciones doctrinales y jurisprudenciales, mayoritarias en nuestro país, en el sentido de que la nuestra no es una democracia militante o combativa, sino una democracia inerme, pues en nuestro ordenamiento jurídico no es equiparable al alemán, donde no existe una disposición semejante al art. 21.1. de la Ley Fundamental y, además, es posible la reforma total de la Constitución, pues no existen límites materiales expresos.

Con ser ciertos estos planteamientos, también hay que señalar que cuando no se producen estas circunstancias que se dan en el modelo alemán, ello no quiere decir que estamos en presencia de un sistema democrático inerme, pues toda democracia es, por naturale$z a$, una democracia militante, que debe contar con los mecanismos suficientes para proceder a su defensa. $Y$ es que toda democracia es militante o no es democracia, con independencia de cual sea el procedimiento de reforma constitucional establecido y la ausencia o no de límites materiales expresos a dicha reforma. Otro problema es determinar cuál sea el contenido de esa democracia militante, dada la regulación constitucional existente en nuestro país. A este respecto, la redacción de los arts. 6 y $9.1 \mathrm{CE}$, que ciertamente no suponen una adhesión ideológica ni una conformidad con el contenido total de la Constitución, permiten una interpretación en este sentido y que los planteamientos doctrinales y jurisprudenciales deben ir en esa línea, abandonando las tesis mantenidas hasta el momento presente. Es decir, a los partidos políticos, dada su naturaleza y relevancia constitucional, les es exigible un comportamiento ejemplar con los principios constitucionales, diferente y distinto del de otras asociaciones políticas, más próximo al de los poderes públicos que al de los ciuda- 
danos, aunque también sea lícito afirmar que los partidos políticos pueden promover medios alternativos de convivencia a los establecidos en la Constitución, pudiendo proponer ṕroyectos políticos diversos que incluso cuestionen el modo de organización actual de un Estado, siempre cuando no supongan un ataque a la propia naturaleza de la democracia, si bien ello sólo pueden hacerlo como declaración programatica, siempre a través de los medios legalmente establecidos $y$ nunca violando el ordenamiento jurídico. Todo ello, teniendo en cuenta que la decisión de ilegalizar un partido afecta a la misma esencia de la democracia, razón por la cual hay que mantener una posición escrupulosamente garantista. Es decir, la lealtad constitucional exigible a los partidos políticos, sin entrar ahora a desentrañar las consecuencias jurídicas de la misma, ni la distinción dogmática entre la lealtad al Estado y la lealtad a la Constitución, parece conducir a esta conclusión, pues no creemos en aquellos postulados doctrinales que hablan únicamente de un respeto formal a la legalidad constitucional, ya que, según ellos, la Constitución es, ante todo, un procedimiento de toma de decisiones y no las decisiones mismas, razón por la cual basta con respetar las reglas de juego para poder subvertir el orden constitucional. Nuestra postura, además, parece plenamente coherente con la jurisprudencia delTEDH, cuando señala que si bien un partido político puede hacer campaña a favor de un cambio de la legislación o de las estructuras legales y constitucionales del Estado, ello ha de hacerse a través de medios legales y democráticos y el cambio propuesto ha de ser compatible con los principios democráticos fundamentales (Sentencias de 30 de julio del 2001, 9 de abril del 2002, entre otras muchas).

Sin embargo no ha sido este el planteamiento mayoritario de nuestra doctrina, que ha negado la existencia de un principio constitucional con valor normativo autónomo, lo cual es cierto, y nuestra jurisprudencia, pues las tesis contrarias han llegado hasta la elaboración de la actual Ley de Partidos y su aplicación práctica. En efecto, ya en los diferentes informes preceptivos al proyecto de ley, emitidos por el Consejo de Estado y el Consejo General del Poder Judicial, se mantenían las tesis de una ausencia de democracia militante, razón por la cual no se prohibían la defensa de ideas o doctrinas sino únicamente la actuación contraria de los partidos políticos a los principios constitucionales. Por otro lado, ya la Sentencia del Tribunal Supremo de 29 de mayo de 1997 iniciaba una línea que iba a ser seguida posteriormente. Así, la STC $43 / 2003$ señala que uen nuestro ordenamiento jurídico no tiene cabida un modelo de democracia militante en el sentido que él le confiere, esto es, un modelo en el que se imponga, no ya el 
respeto, sino la adhesión positiva al ordenamiento $y$, en primer lugar a la Constitución. Falta para ello el presupuesto inexcusable de la existencia de un núcleo normativo inaccesible a los procedimientos de reforma constitucional que, por su intangibilidad misma, pudiera erigirse en parámetro autónomo de corrección jurídica, de manera que la sola pretensión de afectarlo convirtiera en antijurídica la conducta que, sin embargo, se atuviera escrupulosamente a los procedimientos normativos». Esta misma línea argumental es seguida por la Sentencia del Tribunal Supremo de 27 de marzo del 2003, cuando señala que «nuestro sistema político responde a un régimen de libertad política prácticamente ilimitada (absolutamente ilimitada en las ideas, no así en los actos a través de los que se pretenda su consecución), adquiriendo pleno sentido que nuestra Constitución no haya optado por un sistema de democracia militante, sino por un sistema extremadamente tolerante, si se quiere combativamente tolerante, a favor de todos los postulados políticos", concluyendo que la defensa de sus postulados por parte de los partidos políticos debe hacerse respetando la legalidad y por los cauces democráticos, nunca a través de la violencia $y$ nunca cercenando los derechos fundamentales de los demás.

\section{Los partidos políticos y los derechos fundamentales}

El Derecho de Partidos es consustancial al sistema de derechos fundamentales y libertades publicas constitucionalmente garantizado. $Y$ ello tanto por lo que se refiere a la naturaleza de los partidos como asociaciones políticas, como por la implicación, en su posición constitucional y en su régimen jurídico, de numerosos derechos fundamentales, entre los cuales merecen destacarse los siguientes.

a) El derecho de asociación política. Nuestra doctrina y nuestra jurisprudencia constitucional, desde sus orígenes (SSTC 3/1981, $10 / 1982,10 / 1983 \ldots)$, ha señalado que los partidos políticos son entes privados de base asociativa, no admitiendo la consideración de órganos constitucionales ni siquiera de poderes públicos, aunque realizan funciones de una importancia constitucional primaria, siendo instrumentos fundamentales de la acción del Estado. Esta tesis ha sido sustancialmente mantenida en la STC 43/2003, de 12 de marzo, donde tras señalar que los partidos políticos se cualifican, en tanto que asociaciones, por la relevancia constitucional de sus cometidos, señala que sobre su naturaleza asociativa se eleva "una realidad institucional 
diversa y autónoma que, en tanto que instrumento para la participación política en los procesos de conformación de la voluntad del Estado, justifica la existencia de un régimen normativo propio, habida cuenta de la especificidad de esas funciones. La relevancia constitucional de los partidos les viene dada por pretender un fin cualificado de interés publico y de cuya aspiración se sirve el Estado para proveer a la integración de los procedimientos de formación de la voluntad general. La libertad característica de las asociaciones, y de la que los partidos también disfrutan, no puede ser para estos tan omnimoda que a su amparo se desvirtúen como instrumentos para la consecución de sus fines constitucionales". "Los partidos - concluye la Sentenciason así, unas instituciones jurídico-políticas, elemento de integración entre lo social y lo jurídico que hace posible la integración entre gobernantes y gobernados, ideal del sistema democrático... y de la que ha de resultar un ordenamiento integrado por normas que si en su procedimiento formal de elaboración han de ajustarse a la racionalidad objetiva del Derecho positivo, en su contenido material se determinan por el juego de la mayorías que en cada momento respalden las diferentes opciones ideológicas y políticas, conformadas y aglutinadas por los partidos a través de la concurrencia de sus programas de gobierno en los distintos procesos electorales".

Ello significa que una parte sustancial del Derecho de Partidos viene determinada por el régimen general de las asociaciones políticas, razón por la cual la LODE se convierte en norma supletoria de la LOOP. Ahora bien, el legislador puede establecer un régimen jurídico especial para los partidos políticos, como consecuencia directa de su posición constitucional, gozando de determinados privilegios frente a las asociaciones en general y que integran el llamado "privilegio de partido" y cuyas manifestaciones más importantes son las siguientes: la creación de partidos políticos esta sujeta a las mismas garantías constitucionales que el derecho de asociación política, especialmente por lo que se refiere a la posibilidad de recurso de amparo ante el Tribunal Constitucional; les es exigible un plus adicional de actuación en relación con los principios democráticos en los términos apuntados anteriormente, como pudiera ser la exigencia de que su estructura interna y funcionamiento fuesen democráticos, aunque esta exigencia no se predica exclusivamente de los partidos políticos, sino que se ha extendido a todas las asociaciones; la posibilidad de un fuero jurisdiccional especial, que en el modelo alemán se atribuye únicamente al Tribunal Constitucional y que en nuestro ordenamiento jurídico es competencia de la jurisdicción ordinaria, aunque la competencia atribuida a la Sala Especial del Tribunal Su- 
premo también pudiera, en cierta medida, revestir tal carácter; $y$ un largo etcétera.

b) La libertad ideológica, concebida como el derecho de todo ciudadano a la formación de un sistema de ideas que representan una determinada concepción global del mundo. En su condición de libertad de pensamiento, la libertad ideológica carece de límite alguno. Es decir, la Constitución no limita la libertad ideológica, sino sólo su manifestación, garantizándose cualesquiera ideologia, incluso la contraria a la Constitución. Ello no quiere decir que no existen principios ideológicos subyacentes al texto constitucional, pues el mismo responde a una ideología democrática, dentro de la cual tienen cabida las distintas opciones politicas. $Y$ esa ideología constitucional permite la existencia de ideologías contrarias a la misma, siempre que no se incurra en el ilícito penal correspondiente.

Como señala nuestra jurisprudencia constitucional (STC 20/1990), "la libertad ideológica indisolublemente unida al pluralismo político que, que como valor esencial de nuestro ordenamiento jurídico propugna la Constitución, exige la máxima amplitud en el ejercicio de aquella y, naturalmente, no sólo en lo coincidente con la Constitución y con el resto del ordenamiento jurídico, sino también en lo que resulte contrapuesto a los valores y bienes que en ellos se consagran, excluida siempre la violencia para imponer los propios criterios, pero permitiendo la libre exposición de los mismos en los términos que impone una democracia avanzadan. Es decir, resulta perfectamente legítimo discrepar de los contenidos constitucionales. Esta jurisprudencia es plenamente coherente con la establecida por elTEDH, para quien la democracia es un elemento fundamental del orden público europeo, razón por la cual debe respetarse el pluralismo y el libre debate de las ideas, irrenunciable por el propio soberano.

c) La libertad de expresión esta indisolublemente unidad a la libertad de opinión, la cual para adquirir auténtica relevancia juridica tiene que manifestarse. Nuestra jurisprudencia constitucional ha señalado que la libertad de expresión garantiza un interés constitucional: la formación y existencia de una opinión publica y libre, ya que, al ser una condición previa y necesaria para el ejercicio de otros derechos inherentes al funcionamiento del sistema democrático, se convierte, a su vez, en uno de los pilares de la sociedad libre y democrática (STC 159/1986, por todas). Es decir, nuestra jurisprudencia ha atribuido un carácter preferente a la libertad de expresión, que es perfectamente deslindable de la apología, en el sentido atribuida a esta por nuestra jurisprudencia ordinaria (STS de 4 de julio de 1994) cuando distingue 
entre la lícita "apología de la ideología" y la ilícita "apología del delito o del delincuente», entendiendo por la primera una coincidencia genérica con un ideario y por la segunda la exaltación y justificación de unos hechos criminales concretos o de sus autores.

d) El derecho de participación política. Como es sabido la participación y la representación son dos realidades inescindibles. Nuestra Constitución opta claramente por el sistema representativo, prohibiendo toda manifestación de mandato imperativo. A este respecto, nuestra jurisprudencia constitucional, desde sus primeras Sentencias (SSTC 5/1983, 1071983, 16,1983,20/1983...) ha venido señalando que el derecho a participar corresponde a los ciudadanos y no a los partidos, que los representantes elegidos lo son de los ciudadanos y no de los partidos y que la permanencia en el cargo no puede depender de la voluntad de los partidos, sino de la expresada por los electores, los cuales están representados por la totalidad de los ciudadanos y no únicamente por aquellos en quienes depositaron su confianza mediante el acto de la votación. Esta tesis, constitucionalmente correcta, parece presentar ciertas dosis de falta de adecuación a la realidad política, dando lugar a conocidos casos de transfuguismo y corrupción política. Por ello, cada vez que esto se produce, se alzan voces a fin de propiciar cambios normativos o jurisprudenciales en el sentido de dejar de proteger al representante individualmente considerado y someterlo a la disciplina del partido, por cuyas listas fue elegido, $y$ al programa político por el que fue votado por los electores. Buena prueba de ello, son las propuestas, todas ellas rechazadas, presentas en el ultimo debate sobre el estado de la nación a primeros de julio del 2003. Frente a estas tesis, las soluciones jurídicas no son fáciles. Prueba de ello es que únicamente se han conseguido cuotas muy parciales, tales como las limitaciones realizadas en torno a los cambios de grupo parlamentario al comienzo de cada legislatura. Mayor alcance parecen tener las medidas de carácter político, siempre pensando que los electores suelen castigar a quienes han quebrantado su fidelidad al partido político, tales como el acuerdo sobre un Código de conducta politica en relación con el transfuguismo en las Corporaciones Locales, suscrito el 7 de julio de 1998 por la mayoría de las fuerzas políticas, que debe extenderse a todos los ámbitos del sistema representativo y profundizar en su contenido y significado.

e) El derecho a la tutela judicial efectiva, presente en casi todos los recursos de amparo substanciados ante elTribunal Constitucional, y que a lo largo de la impugnación de la LOPP y de su aplicación práctica ha tenido sus manifestaciones más importantes en el derecho a juez ordinario predeterminado por la ley, en el derecho a la ejecución 
de sentencias, en la prohibición de indefensión, en la presunción de inocencia, etc.

\section{El régimen juridico de los partidos políticos}

La posición constitucional de los partidos políticos a la que antes nos hemos referido determina la existencia de un régimen jurídico propio, diferente del de las asociaciones políticas, cuyo régimen general también les es aplicable, y que se manifiesta en las siguientes cuestiones.

Por lo que se refiere a la creación de partidos políticos, ła hemos señalado que el principio de libertad despliega aquí su máxima eficacia, únicamente limitado por las previsiones constitucionales existentes y que limitan a determinados colectivos la pertenencia a partidos políticos (arts. 127, 159.4 CE). A este respecto, nuestra Ley de Partidos, a nuestro juicio de forma poco acertada, contiene importantes diferencias en relación con la regulación efectuada por la LODE, entre las cuales destacan la exclusión de las personas juridicas y de los extranjeros, los cuales si que pueden afiliarse a los partidos políticos ya creados.

Mayores críticas parece merecer el tema de la inscripción y de la adquisición de la personalidad jurídica, donde las diferencias con el régimen general del derecho de asociación son más evidentes. En estas cuestiones la legislación de nuestra transición política había pasado del sistema del registro previo, al establecimiento de un mecanismo puramente administrativo, a un modelo prevalentemente judicial, cuya competencia corresponde a la jurisdicción contencioso-administrativa. En efecto, el atribuir a la inscripción un carácter constitutivo y no declarativo y hacer de la misma conditio sine qua non para la adquisición de la personalidad jurídica, cuya plena constitucionalidad ha sido confirmada por nuestra jurisprudencia constitucional, parece contradecirse con la consideración de la creación de partidos políticos como un auténtico derecho de libertad. Ello puede conducir a que un partido político cuya inscripción sea denegada tenga que realizar su actuación política como simple asociación, con las consecuencias juridicas (participación en los procesos electorales, acceso a la financiación publica, etc..) que de ello se derivan. Todo ello sin olvidar otras cuestiones, como las importantes potestades del Ministerio del Interior, sobre las cuales ya se había pronunciado de forma reiterada nuestra jurisprudencia constitucional bajo la vigencia de la Ley de Partidos 
de 1978, y que continúan manteniéndose en la actual Ley de Partidos, habiéndose, asimismo, reafirmado su plena constitucionalidad en las ultimas decisiones adoptadas por el Tribunal Supremo y por el Tribunal Constitucional.

En cuanto a la exigencia de que su estructura interna y funcionamientos sean democráticos, nuestra jurisprudencia constitucional (STC 10/1983) ya había señalado que ello constituía una carga impuesta a los propios partidos con la finalidad de «asegurar el efectivo cumplimiento de las funciones que estos tienen constitucional y legalmente encomendadas $y$, en último término, contribuir a garantizar el funcionamiento democrático del Estado». Es decir, esta exigencia parece ser uno de los contenidos del llamado privilegio de partidos, aunque esta tesis hoy día debe considerarse perfectamente superada, pues dicha exigencia se predica también de los sindicatos y asociaciones profesionales, para los colegios profesionales y para las organizaciones profesionales que contribuyan a la defensa de intereses económicos (arts. 7, 36 y 52 CE) y, lo que es más revelador, ha sido extendida por la LODE a todas las asociaciones (art. 2.5.), exigiéndose, además, un pleno respeto al pluralismo. Quizás a ello no sea ajena nuestra propia jurisprudencia constitucional cuando manifiesta que el derecho de asociación referido a los partidos políticos tiene una cuarta dimensión respecto al contenido genérico del derecho de asociación, consistente en el derecho de participación democrática de los afiliados, de modo que el principio democrático se traduce fundamentalmente en la garantía de los derechos de participación de los afiliados que se integra en el contenido del art. $22 \mathrm{CE}$.

La exigencia de una estructura interna y funcionamientos democráticos es un concepto jurídico indeterminado, que la Ley de Partidos de 1978 contemplaba de una forma mínima y escasa, tal y como fue puesto de relieve por nuestra doctrina y por nuestra jurisprudencia (SSTC $85 / 1986,218 / 1988,56 / 1995 . .$.$) y que la actual LOPP ha amplia-$ do, de una forma poco sistemática, aunque sin llegar las previsiones realizadas por nuestra doctrina científica a las contenidas en la LODE. Esta exigencia debe ser compatible con el derecho de autoorganización de los partidos políticos, verdadera expresión de los principios de libertad y de intervención mínima a que anteriormente nos referíamos, y con los derechos de los afiliados, que reciben un tratamiento más pormenorizado que en la ley de 1978. La ausencia de democracia interna es uno de los supuestos de disolución de los partidos políticos, encomendándose su competencia a la Sala Especial del Tribunal Supremo. 
La exigencia de democracia interna no puede confundirse con la actividad externa o exterior del partido, a la cual no se refiere el art. 6 CE, pero sí tanto la Ley preconstitucional de 1978 como la actual Ley de Partidos, y cuya exigencia, a nuestro juicio, no parece plantear problema alguno de constitucionalidad.

Por lo que se refiere a la disolución de los partidos, esta puede ser voluntaria, la cual no podrá acordarse cuando se haya iniciado un proceso de declaración judicial de ilegalidad, o por declaración judicial en los términos expresamente señalados, debiendo distinguirse entre el órgano competente, al que nos referiremos posteriormente, $y$ las causas o supuestos de disolución. En principio, hay que señalar que con la legislación anterior era casi imposible ilegalizar a un partido político que no figurase como asociación ilícita. $Y$ ello, pese a las previsiones de la Ley de 1978 (art. 5.2. b), que dejaba un amplio margen a la libertad de apreciación del juez, bajo cuya vigencia se intento en dos ocasiones la ilegalización de Batasuna. El primero fue con motivo de la denegación de la inscripción por no constar en ella un acatamiento expreso a la Constitución, denegación que fue rechazada por la Sentencia del Tribunal Supremo de 23 de mayo de 1984, de su Sala Tercera. La segunda, como consecuencia de la demanda formulada por el Ministerio Fiscal por apreciar en sus Estatutos indicios racionales de ilicitud penal. La Sala Primera del Tribunal Supremo, en Sentencia de 13 de mayo de 1986, rechazó dicha demanda, señalando que es en el ámbito de las actividades del partido donde debe comprobarse su respeto por el ordenamiento jurídico.

Lo primero que hay que señalar en relación con el sistema diseñado por la LOOP es que el modelo español, a diferencia de otros, no permite ilegalizar a un partido político por su ideología, sino sólo por sus actividades contrarias a los principios democráticos, siempre que estas sean realizadas de forma reiterada y grave. La Ley distingue entre los fines perseguidos (vulnerar los principios democráticos, deteriorar o destruir el régimen de libertades e imposibilitar o eliminar el sistema democrático), conductas que acreditan tales fines (arts. 9.2 y 9.3) $y$ unos medios para probar tales conductas (art. 9.4), entre los cuales se encuentra la trayectoria histórica de un partido político. Estamos en presencia de un modelo garantista, donde se contemplan, de forma taxativa y cerrada, los supuestos y causas que determinan la ilegalización, no siendo necesario la concurrencia de todas y cada una de las causas, ni la repetición de una misma conducta, ni una identidad de sujetos y acciones. Lo fundamental es la vulneración de los principios democráticos y para ello la ley enumera, eso sí con escasa sistemática, un amplio elenco de conductas. 
La enumeración de estas conductas, que pueden cometerse por acción o por omisión y que quizás resulte excesivamente casuística y pretendidamente omnicomprensiva, ha sido ampliamente criticada por la primera doctrina, señalando que estamos en presencia de conceptos jurídicos indeterminados; que no respetan el principio de proporcionalidad, pues la disolución únicamente debe reservarse para los supuestos más graves; su posible coincidencia con los tipos penales y presunta vulneración del principio non bis idem; que supone un control ideológico de los partidos; etc... cuestiones todas ellas que han sido rechazadas por nuestra jurisprudencia constitucional y ordinaria, realizando una interpretación distinta de cada una de las causas, que consideran plenamente compatible con la libertad ideológica, de participación y de expresión de los partidos políticos, pues la reiteración y gravedad exigidas son suficientes garantías al respecto. Como señala la Sentencia del Tribunal Supremo de 27 de marzo del 2003, "estas conductas, que si fueran realizadas separadamente probablemente llevarían a declarar que están realizadas en el puro marco de la libertad de expresión y el derecho que todo ciudadano tiene, en un contexto de amplio pluralismo, incluso a errar en sus percepciones políticas, sin embargo, cuando son ejecución de una estrategia marcada desde el terrorismo se convierten en una manifestación más de aquel reparto de tareas con él».

En cuanto al control judicial, los problemas jurídicos planteados también son importantes. En primer lugar, hay que poner de manifiesto la clara opción de nuestra Constitución por atribuir al Poder judicial la competencia para la disolución de los partidos políticos, correspondiendo al Tribunal Constitucional únicamente el conocimiento de los recursos de amparo, opción judicial plenamente confirmada por nuestra jurisprudencia constitucional y que parece ser un argumento más para la inexistencia del llamado "privilegio de partido» en nuestro ordenamiento jurídico, aunque la atribución a la Sala Especial del Tribunal Supremo efectuada. por la LOPP también puede ser considerada como una manifestación del mismo. Estamos en presencia, pues, de un control de legalidad y no de un control de constitucionalidad. A lo largo de la vigencia de la legislación anterior han intervenido, en el control judicial de los partidos políticos, las jurisdicciones penal, civil y contencioso-administrativa. En la actualidad, nos encontramos con las siguientes jurisdicciones competentes:

a) La jurisdicción penal, cuando un partido político incurra en los supuestos de asociación ilícita en los términos del art. 515 del Código Penal.. Bajo la vigencia de la Ley de 1978, el Tribunal Supremo, en Sentencia de 1 de diciembre de 1997, 
condenó a los integrantes de la Mesa nacional de HB a siete años de cárcel por un delito de colaboración con banda armada y a la suspensión de cargo publico y derecho de sufragio durante el tiempo que durase la condena, por haber distribuido un vídeo elaborado por ETA en las televisiones para utilizarlo como cuña electoral en los espacios electorales gratuitos. Posteriormente, el Tribunal Constitucional, al resolver el recurso de amparo planteado, en su Sentencia 136/1999, se manifestó conforme con la doctrina establecida por el Tribunal Supremo, pero estimó parcialmente el amparo por considerar inconstitucional el art. 174 bis del Código Penal de 1973, por razón de la falta de proporcionalidad de la pena. Esta vía penal también ha sido recientemente utilizada por los Autos de 16 de agosto y 6 de septiembre del 2002, del Juzgado de Instrucción num 5 de la Audiencia Nacional, que decreto la suspensión provisional de las actividades de batasuna durante el plazo de tres años, ordenando el cierre de sus locales, la suspensión de las actividades como grupos políticos en el seno de las instituciones representativas y la denegación de las subvenciones que pudieran percibir.

b) La jurisdicción contencioso-administrativa, en los casos de denegación de la inscripción en el registro y en los supuestos previstos en la LODE (art. 39).

c) La jurisdicción civil en lo relativo al trafico jurídico privado de las asociaciones $y$ en lo relativo a las violaciones de los derechos de los afiliados en los términos de la LODE (art. 40).

d) La Sala Especial delTribunal Supremo, prevista en el art. 61 de la LOPJ, cuando vulnere de forma continuada, reiterada y grave, la exigencia de una estructura interna y un funcionamiento democráticos y cuando de forma reiterada y grave su actividad vulnere los principios democráticos o persiga deteriorar o destruir el régimen de libertades o imposibilitar o eliminar el sistema democrático mediante las conductas a que se refiere el art. 9 de la Ley. Asimismo, es competente para el conocimiento de los recursos contencioso-electorales que se presenten contra la proclamación de candidaturas por parte de las agrupaciones de electores que, de hecho, vengan a continuar o suceder las actividades de un partido político declarado judicialmente ilegal y disuelto, o suspendido. En ambos casos, la legitimación corresponde al Ministerio Fiscal y al Gobierno, el 
cual podrá ser instado, únicamente en el primero de los casos, por el Congreso de los Diputados o el Senado, tal y como sucedió con la resolución aprobada por el Congreso de los Diputados el 26 de agosto del 2003, mediante la cual se insta al Gobierno a presentar una demanda ante el Tribunal Supremo para ilegalizar Batasuna, que fue decretada por la Sala Especial en su Sentencia de 27 de marzo del 2003.

La competencia atribuida a la Sala Especial del Tribunal Supremo ha recibido importantes críticas doctrinales pues no parece corresponderse con las competencias que el art. 61 LOPJ le atribuye, aunque difícilmente puede sostenerse que suponga una violación del derecho al juez ordinario predeterminado por la ley, tal y como ha reconocido nuestra jurisprudencia constitucional. Se trata, pues, de una opción libre del legislador, aunque quizás hubiera sido conveniente atribuirlo a otra Sala del Tribunal Supremo, máxime si pensamos que el procedimiento para instar la declaración de ilegalidad es un procedimiento civil.

En cuanto a los efectos de la disolución, estos son el cese inmediato de toda la actividad del partido político, no pudiendo inscribirse cualquier otro que continúe o suceda la actividad del partido declarado ilegal y disuelto, y la apertura de un proceso de liquidación patrimonial, destinándose el patrimonio neto resultante a actividades de interés social o humanitario,

La utilización de estas vías judiciales, tanto la penal como la de la Sala Especial, además del planteamiento de posibles problemas de preferencia judicial cuando se produzca la eventual coincidencia en el tiempo de dos procedimientos judiciales distintos, han plateando importantes problemas jurídicos, alguno de los cuales están pendiente de solución definitiva, generándose importantes conflictos institucionales.

\section{Los partidos políticos y el Derecho Electoral}

El Derecho Electoral es también una disciplina científica autónoma, pues reúne los mismos requisitos que hemos predicado del Derecho de Partidos, buena parte de cuyo contenido se encuentra recogido en las normas electorales que, desde la aprobación de la Ley Orgánica de Régimen Electoral de 1985 (LOREG), han sido objeto de numerosas reformas parciales, la última operada por la propia LOPP en los términos señalados anteriormente. $Y$ es que los principios inherentes al Derecho Electoral (impedimento del falseamiento de la voluntad popular, la conservación del acto electo, la unidad del acto electo- 
ral, entre otros) configuran una especie de axiología electoral que proporciona a esta disciplina sustantividad propia. Todo ello sin olvidar la importancia del Derecho Electoral en nuestro sistema democrático, pues la Ley Electoral debe ser considerada como una norma primaria y el principio democrático parece desplegar aqui toda su virtualidad y potencialidad, implicando el rechazo de cualquier interpretación formalista de la legislación electoral y optando claramente por una interpretación finalista de la misma.

La regulación por las normas electorales de aspectos sustanciales del Derecho de Partidos, se centra fundamentalmente en la presencia de los mismos a lo largo de todo el proceso electoral, desde la presentación (donde ejercen casi un auténtico monopolio) y proclamación de candidatos, como a lo largo de la campaña electoral, en los actos de votación y escrutinio y como entes legitimados en los diferentes contenciosos electorales.

Como consecuencia del proceso de ilegalización de Batasuna y de la presentación de candidaturas en los comicios locales celebrados el 25 de mayo del 2003, de agrupaciones electorales que se entendian continuadoras del partido político disuelto, se instaron sendos contenciosos electorales por parte de la Abogacía del Estado y del Ministerio Fiscal, que fueron sustancialmente acogidos en la Sentencia, de 3 de mayo del 2003, de la Sala Especial del Tribunal Supremo y, posteriormente, ratificados, por la Sentencia dictada en el correspondiente recurso de amparo por el Tribunal Constitucional de 14 de mayo del 2003, que contiene un importante voto particular, donde llega a cuestionarse la constitucionalidad de la reforma operada en la LOREG por la LOPP. Con independencia del necesario acuerdo con el fondo del asunto, se trata de dos resoluciones judiciales, la del Tribunal Supremo y la del Tribunal Constitucional, que dejan mucho que desear desde un punto de vista jurídico, pues los argumentos utilizados no siempre parecen revestir la solidez jurídica necesaria para fundamentar las decisiones adoptadas.

\section{Los partidos políticos y el Derecho Parlamentario}

También el Derecho Parlamentario, al igual que el Derecho Electoral y el Derecho de Partidos es una disciplina con sustantividad científica propia, habiéndose producido una nueva configuración de sus principios inspiradores desde el tránsito de la autonomía parlamentaria, que aun continua conservando algunas manifestaciones concretas, a la plena judiciabilidad de todos los actos parlamentarios. Como señalábamos anteriormente, también importantes aspectos del Derecho de 
Partidos se encuentran recogidos en las normas integrantes del Derecho Parlamentario, especialmente en los Reglamentos de las Cámaras Legislativas.

En el proceso de ilegalización de Batasuna se han producido importantes problemas jurídicos, con motivo de la disolución de los grupos parlamentarios en el Parlamento de Navarra (rápidamente resuelto mediante la resolución de la Presidencia de la Cámára de 16 de septiembre del 2002, por la cual se incorpora el grupo de Batasuna al grupo parlamentario mixto) y especialmente del País Vasco y de algunas Corporaciones Locales (donde se ofrecieron soluciones dispares, según fuese la fuerza política gobernante). En efecto, tanto el Tribunal Supremo (especialmente los Autos de 20 de mayo y 18 de junio) como la Mesa del Parlamento vasco (que incluso llegó a aprobar, con una clara intención política, un proyecto de resolución de la Presidencia, similar al de Navarra, que, posteriormente, fue rechazado por la Junta de Portavoces) han emitido una serie de resoluciones provocando esta última un conflicto institucional cuyo alcance aún es imposible de prever. Y es que con la utilización de todo tipo de argumentos jurídicos (violación del principio de división de poderes, de la autonomía parlamentaria y su derecho de autoorganizacion, de la inviolabilidad de los parlamentarios, el significado de los Reglamentos Parlamentarios, la diferencia juridica entre grupos parlamentarios Y partidos políticos, del significado del cumplimiento de las resoluciones judiciales y los problemas derivados de la ejecución de las resoluciones del Tribunal Supremo, el significado de determinados tipos penales, como el delito de desobediencia, del planteamiento de querellas criminales y de incidentes de nulidad, y un largo etcétera), se ha creado un conflicto entre diversos poderes públicos como son Tribunal Supremo, el Parlamento Vasco, el Ministerio Fiscal, el Tribunal Superior de Justicia del País Vasco, el Consejo General del Poder Judicial que, además de poner de relieve algunas deficiencias y lagunas de nuestro ordenamiento jurídico, incluida la propia LOPP, parece trascender mas allá de los contenciosos planteados, situándose de lleno en la problemática conflictual del País Vasco.

\section{La financiación de los partidos políticos}

No parecen existir grandes dudas a la hora de afirmar que la financiación de los partidos políticos forma parte del núcleo esencial del Derecho de Partidos y, en consecuencia, debería ser uno de los contenidos típicos de toda Ley de Partidos, pues afecta a la propia natu- 
raleza jurídica de los mismos, a sus relaciones con los poderes públi$\cos$ y al propio proceso de lucha contra la corrupción, donde no siempre la norma jurídica alcanza una eficacia plena. Sin embargo ello no ha sido así, y la legislación sobre financiación de partidos políticos ha tenido un carácter fragmentario y disperso, revelando una clara y absoluta falta de sistemática, sin llegar, por otro lado, a resolver de forma adecuada los problemas planteados.

La Legislación anterior a la actualmente vigente en materia de financiación de partidos políticos únicamente contemplaba aspectos aislados y fragmentados sin regular, en general, los recursos económicos de los partidos políticos, ni contener las normas que garanticen la regularidad y trasparencia de su actividad económica. Así, habría que mencionar la inicial subvención de gastos electorales efectuada en el Real Decreto-Ley 20/1977, de 18 de marzo, sobre normas electorales; la Ley 39/1978, de 17 de julio, de elecciones locales, modificada parcialmente por la Ley Orgánica 6/1983, de 2 de marzo; las normas contenidas en la LOREG y sus sucesivas modificaciones, así como las establecidas en las diversas leyes electorales y autonómicas; la contenida en los diversos Reglamentos Parlamentarios y las establecidas en determinadas disposiciones especiales como la Ley Orgánica $2 / 1988$, de 3 de mayo, reguladora de la publicidad electoral en emisoras de televisión privada; o la Ley Orgánica 10/1991, de 8 de abril, de publicidad electoral en emisoras municipales de radiodifusión sonora.Todo lo cual es revelador de la inestabilidad de las regulaciones jurídicas en materia de financiación de partidos, que se convierte así en la regla general de nuestro ordenamiento jurídico

El art. 6 de la Ley de Partidos de 1978 establecía el principio de financiación publica de los partidos políticos, disponiendo la existencia de una cantidad global en los Presupuestos Generales del Estado y otra cantidad para gastos electorales. Por su parte, la LOOP no hace más que remitirse a la Ley Orgánica 3/1987, de Financiación de Partidos Políticos y a la Ley Orgánica 271982, de 12 de mayo del Tribunal de Cuentas y a la Ley 7/1988, de 5 de abril, de Funcionamiento del Tribunal de Cuentas.

Así pues, la regulación general sobre el tema se encuentra en la Ley Orgánica 3/1987, de Financiación de Partidos Políticos, donde se establecen los recursos procedentes de la financiación publica y privada, regulándose unas mínimas obligaciones contables y estableciéndose una parca regulación sobre la fiscalización y control. Posteriormente esta Ley ha sido reformada por la Ley Orgánica 1/2003, de 21 de mayo, para la garantía de la democracia en los Ayuntamientos 
y la seguridad de las concejales, en la cual, además de modificar otras leyes, se establecen los siguientes extremos:

a) Se niegan los recursos procedentes de la financiación pública a aquellos partidos que, con su actividad, promuevan o justifiquen el odio o la violencia contra las personas, enaltezcan o justifiquen los delitos de terrorismo o a quienes hayan participado en su ejecución, o realicen actos que entrañen el descrédito de las víctimas de los delitos terroristas o sus familiares.

b) También se produce esa denegación cuando en los órganos directivos, grupos parlamentarios de cualesquiera Asambleas representativas o cargos que tengan la condición de electos, figuren personas condenadas por sentencia, aunque no sea firme, por delitos de rebelión, contra las instituciones del Estado o de terrorismo, salvo que hubieran rechazado públicamente los fines y los medios terroristas, en los términos previstos en la legislación penal.

c) También se produce esa ausencia de financiación pública cuando concurriendo las conductas previstas en el artículo 9 de la Ley de Partidos, no proceda por el grado de reiteración o gravedad de las mismas su disolución.

d) Se establece la posibilidad de incluir en los Presupuestos Generales del Estado una asignación anual para sufragar los gastos de seguridad en los que incurran los partidos políticos para mantener su actividad política e institucional.

e) Finalmente, las modificaciones introducidas en la Ley Electoral, $y$ en clara sintonía con las señaladas anteriormente, se produce una denegación de las subvenciones electorales a aquellos partidos políticos que incurran en los mismos supuestos, tengan los órganos directivos o figuren personas condenadas en los términos señalados anteriormente.

Todo ello sin olvidarnos de otras normas que también afectan a la financiación de los partidos como la Ley 43/1998, de 15 de diciembre, de restitución o compensación a los partidos políticos de bienes y derechos incautados en aplicación de la normativa sobre responsabilidad política del período 1936-1939; o la Ley 24/2001, de 27 de diciembre, de medidas fiscales, administrativas y del orden social, cuya Disposición Adicional 23, negaba el pago de las subvenciones a los partidos políticos, en cuyos órganos directivos o listas electorales figurasen personas que hubiesen sido condenadas por sentencia firme por 
pertenencia, actuación al servicio o colaboración con banda armada, si no hubiesen rechazado públicamente los fines y medios de la organización terrorista a la que pertenecieron o con la que colaboraron, apoyaron o exaltaron, regulando, incluso, la imposibilidad legal de ejecución de aquellas sentencias que hubiesen declarado el derecho de tales partidos. Sobre esta disposición ha sido planteada una cuestión de inconstitucionalidad por parte de la Audiencia Nacional y aun no resuelta por nuestroTribunal Constitucional; o la propia Ley Orgánica 1/2002, de 2 de marzo, reguladora del Derecho de Asociación, en cuyo art. 4.6. dispone: "Los poderes públicos no facilitaran ayuda alguna, económica o de cualquier tipo, a aquellas asociaciones que con su actividad promuevan o justifiquen el odio o la violencia contra personas físicas y jurídicas, o enaltezcan o justifiquen por cualquier medio los delitos de terrorismo o de quienes hayan participado en su ejecución, o la realización de actos que entrañen descrédito, menosprecio por humillación de las víctimas de los delitos terroristas o de sus familiares". A tales efectos se considera que una asociación realiza tales actividades cuando alguno de sus órganos de representación, miembros activos de la misma, hayan sido condenados por Sentencia firme por colaboración con banda ramada en tanto no hayan cumplido completamente la condena, si no hubiesen rechazado públicamente los fines y los medios de la organización terrorista con la que colaboró o exaltó.

Todo ello sin olvidar las medidas adoptadas, tras los acontecimientos del 11 de septiembre del 2001, tendentes a evitar la financiación pública de aquellos partidos que ensalcen o no condenen el fenómeno terrorista y a bloquear la financiación de los mismos. Entre las medidas legislativas más importantes podríamos destacar la Ley $13 / 2003$, de 21 de mayo, de prevención y bloqueo de financiacion del terrorismo, mediante la cual se crea la Comision de Vigilancia de Financiación del Terrorismo; la Ley Orgánica 4/2003, de 21 de mayo, complementaria de la anterior; la Ley 32/1999, de 8 de octubre, de Solidaridad con las víctimas del terrorismo.

A lo largo de toda esta normativa, y sin perjuicio de señalar los avances conseguidos, se han planteado numerosos problemas, que tampoco son exclusivos de nuestro país, suficientemente destacados ya por la doctrina y sobre los cuales no parece necesario insistir aquí y ahora. Cuestiones tales como una delimitación clara de lo que ha de ser la financiación pública directa, que ha de estar sujeta a determinados limites; la necesaria incentivación de la financiacion privada y el control de la misma; la imperiosa necesidad de reducir la financiación por gastos electorales; las mejoras necesarias a introducir en el control interno por parte de los partidos políticos, especialmente por 
lo que a las subvenciones finalistas se refiere; el establecimiento de mecanismos claros de control y transparencia, tratando de impedir todo tipo de financiación irregular; la radical transformación que se ha de operar en el control realizado por el Tribunal de Cuentas; el establecimiento de sanciones eficaces por el incumplimiento de las normas de financiación de los partidos; la regularización de la deuda pendiente de los partidos políticos; la necesidad de elaborar un código ético sobre la financiacion de la actividad pública, apoyado por un fuerte consenso social que condene las prácticas irregulares; el fomento de la autofinanciación de los partidos políticos mediante los correspondientes incentivos fiscales; y un largo etc., son todas ellas cuestiones que aun continúan pendientes entre nosotros y sobre las cuales los partidos políticos mayoritarios, sin duda los grandes beneficiarios de la financiación pública y privada, parecen imponer la ley de la inercia. 